\title{
Avaliação Microbiológica de Gelatina Extraída de Pele de Tilápia do Nilo (Oreochromis niloticus)
}

Monique de Oliveira Maia (I), Daniele Maria Alves Teixeira Sá (I), Marlene Nunes Damaceno (I), Monique Ellen Torres da Silva (I), Anakláudia Sombra Santos (I), Gilnara Lima Bandeira (I), Mônica de Oliveira Maia (I), Virna Luiza de Farias (I), Renata Chast Chastinet Braga (I), Herculana Carvalho Castro (I)

(I) IFCE - Instituto Federal do Ceará (Rua Estevão Remígio, 1145, Centro, 62930-000, Limoeiro do Norte, Ceara, Brasil.)

\section{Resumo}

É cada vez mais frequente na sociedade atual a atenção aos conceitos de sustentabilidade e gestão ambiental, além do alerta às indústrias de diversos ramos em relação ao controle e gerenciamento de resíduos. A indústria pesqueira no Nordeste brasileiro, por exemplo, possui uma grande geração de resíduos, caracterizada principalmente por partes não aproveitáveis do pescado (peles, ossos, cabeças, vísceras). Pesquisadores têm concentrado seus estudos na obtenção de gelatina a partir da pele de animais aquáticos. Além de minimizar a geração de resíduos essa alternativa é vantajosa para povos que não apreciam ou possuem restrições a produtos de mamíferos. Com isto, o presente estudo objetivou analisar gelatina extraída de pele de Tilápia do Nilo (Oreochromis niloticus) através de avaliação microbiológica. A gelatina foi extraída com pré tratamento alcalino utilizando Hidróxido de Sódio 0,3\% seguido de tratamento Ácido Sulfúrico $0,3 \%$ e Ácido cítrico $0,7 \%$. Com posterior extração em banho maria a $50^{\circ} \mathrm{C}$ por uma hora. Após a obtenção do gel as amostras foram levadas à geladeira para gelificação. Foram retiradas alíquotas para realização de análises microbiológicas de Coliformes Totais e a $45^{\circ} \mathrm{C}$; Contagem de Aeróbios mesófilos, Staphylococcus aureus e Salmonella spp. O processo de extração e de realização das análises se deu em quatro repetições. De

\footnotetext{
Referência:

Monique de Oliveira Maia, Daniele Maria Alves Teixeira Sá, Marlene Nunes Damaceno, Monique Ellen Torres da Silva, Anakláudia Sombra Santos, Gilnara Lima Bandeira, Mônica de Oliveira Maia, Virna Luiza de Farias, Renata Chastinet Braga (I), Herculana Carvalho Castro (I). Avaliação Microbiológica de Gelatina Extraída de Pele de Tilápia do Nilo (Oreochromis Niloticus). In: Anais do $12^{\circ}$ Congresso Latinoamericano de Microbiologia e Higiene de Alimentos MICROAL 2014 [= Blucher Food Science Proceedings, num.1, vol.1]. São Paulo: Editora Blucher, 2014. DOI 10.5151/foodsci-microal-142
} 
acordo com os valores microbiológicos preconizados pela Resolução vigente (RDC 12 de Janeiro 2001), a gelatina se mostrou com ótimos resultados, dando valores Staphylococcus aureus, ausência de Salmonella spp. em $25 \mathrm{~mL}$ da amostra, resultados negativos em todos os tubos do teste presuntivo, ou seja, sem contaminação por coliformes, e com valores mínimos de bactérias aeróbias mesófilas variando de 40 a 540 UFC g-1. Tal resistência a contaminação pode ser atribuída aos tratamentos na extração e à possíveis condições ácidas do meio, que podem ter contribuído para inibir de forma considerável o crescimento microbiano. Os dados obtidos nas análises microbiológicas foram considerados satisfatórios, uma vez que a gelatina extraída não apresentou contaminação pelos microrganismos estudados. Ressalta-se a importância de estudos futuros em relação às concentrações dos compostos químicos utilizados.

Palavras-Chave: Contaminação, extração, gel, pescado. Agência de Fomento: CNPq, Capes e Funcap 